\title{
The influenza virus NS1 protein: a novel inhibitor of pre-mRNA splicing
}

\author{
Yuan Lu, Xiao-Yan Qian, and Robert M. Krug \\ Rutgers University, Department of Molecular Biology and Biochemistry, Piscataway, New Jersey 08855-1179 USA
}

\begin{abstract}
We have shown previously that the influenza virus NS1 protein inhibits the nuclear export of mRNAs. Here we demonstrate that the NS1 protein also regulates another post-transcriptional step: It inhibits pre-mRNA splicing both in vivo and in vitro. The mode by which the NS1 protein inhibits pre-mRNA splicing is novel. The pre-mRNA forms spliceosomes, but subsequent catalytic steps in splicing are inhibited. Affinity selection experiments establish that the NS1 protein is associated with the spliceosomes that are formed. The RNA-binding domain of the NS1 protein is required for the inhibition of splicing and for the interaction of the protein with spliceosomes. Because the NS1 protein is associated with U6 snRNA in influenza virus-infected cells as well as in splicing extracts from uninfected cells, it is likely that the NS1 protein also inhibits pre-mRNA splicing in infected cells. Surprisingly, the splicing of the viral ns 1 mRNA, the very mRNA that encodes the NS1 protein, was resistant to inhibition by the NS1 protein. This resistance is conferred by sequences in ns1 mRNA.
\end{abstract}

[Key Words: Influenza virus NS1 protein; pre-mRNA splicing; spliceosome; U6 snRNA]

Received May 12, 1994; revised version accepted June 16, 1994.

Eukaryotic pre-mRNAs synthesized by nuclear RNA polymerase II undergo a series of post-transcriptional processes. Two of these processes are pre-mRNA splicing and mRNA export from the nucleus, both of which can be regulated (Green 1989; Krug 1993). Alternative splicing, whereby different mRNAs are generated from a single pre-mRNA, has been shown to be regulated by proteins that bind to specific regions of the pre-mRNA precursor. In many instances it has been shown that specific proteins act on specific pre-mRNA targets to regulate their alternative splicing. For example, in the Drosophila sex determination pathway, a specific protein $(\mathrm{s})-$ sex lethal protein or the complex of the Tra and Tra2 proteins-binds to a specific site on a particular premRNA to either suppress or activate, respectively, the usage of a 3' splice site (Baker 1989; Inoue et al. 1990; Bell et al. 1991; Tian and Maniatis 1992).

The nuclear export of unspliced pre-mRNAs and spliced mRNAs can also be regulated by specific proteins. Usually unspliced pre-mRNAs are not exported from the nucleus, apparently at least in part because the pre-mRNAs are efficiently committed to spliceosome formation in the nucleus (Legrain and Rosbash 1989). However, this process is overcome in the case of the pre-mRNAs of human immunodeficiency virus-1 (HIV1) and other lentiviruses by the action of the virus-encoded Rev (or Rev-like) protein, which binds to a specific RNA sequence (RRE, or Rev responsive element) in the viral pre-mRNAs and facilitates their nuclear export (Hadzopoulou-Cladaras et al. 1989; Hanly et al. 1989; Malim et al. 1989). The influenza virus NS1 protein has the opposite effect on the nuclear export of mRNA: It inhibits the transport of mRNAs (Alonso-Caplen et al. 1992; Fortes et al. 1994). The NS1 protein binds to the poly(A) sequence at the 3' ends of mRNAs and inhibits the nuclear export of all poly(A)-containing viral and cellular mRNAs (Qiu and Krug 1994).

In the present report we demonstrate that the influenza virus NS1 protein not only inhibits the nuclear export of poly(A)-containing mRNAs but also inhibits the splicing of pre-mRNAs both in vivo and in vitro. By analysis of the in vitro splicing reaction we show that the NS1 protein inhibits pre-mRNA splicing in a novel way. Furthermore, we present evidence strongly suggesting that the NS1 protein also inhibits pre-mRNA splicing in influenza virus-infected cells.

\section{Results}

The influenza virus NS1 protein inhibits pre-mRNA splicing in vivo

To determine whether the NS1 protein affects premRNA splicing in vivo, 293 cells were transfected with two vectors: one specifying the NSl protein via an unspliceable ns1 mRNA and one specifying a globin minigene pre-mRNA. At $40 \mathrm{hr}$ after transfection, the cells were fractionated into nuclear and cytoplasmic fractions, and the amount of unspliced and spliced globin mRNAs in these two cellular fractions was determined by $\mathrm{S} 1$ analysis (Fig. 1A,B). In the absence of the NS1 protein essentially all of the globin pre-mRNA was spliced and transported to the cytoplasm. In contrast, in 
Lu et al.

A

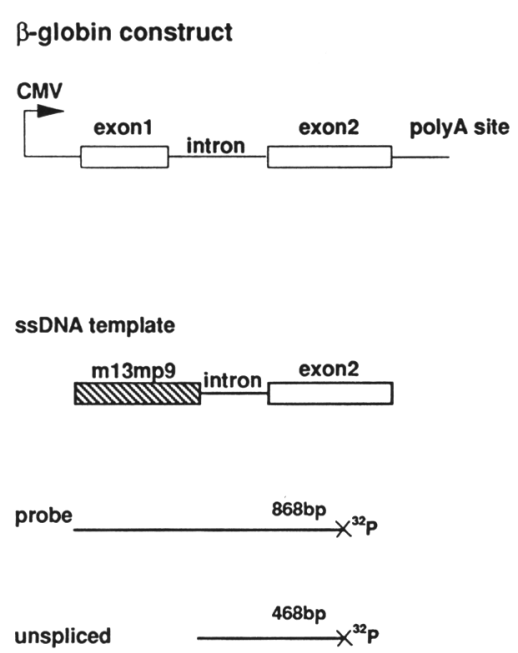

spliced
B $\beta$-globin
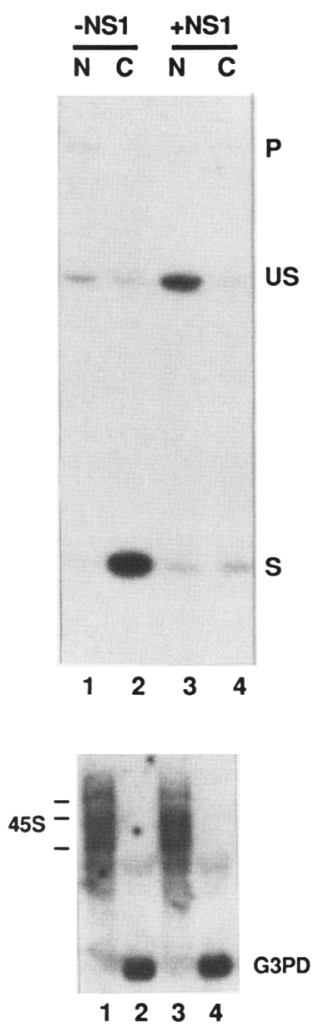

C $\beta$-globin

D SV40-T
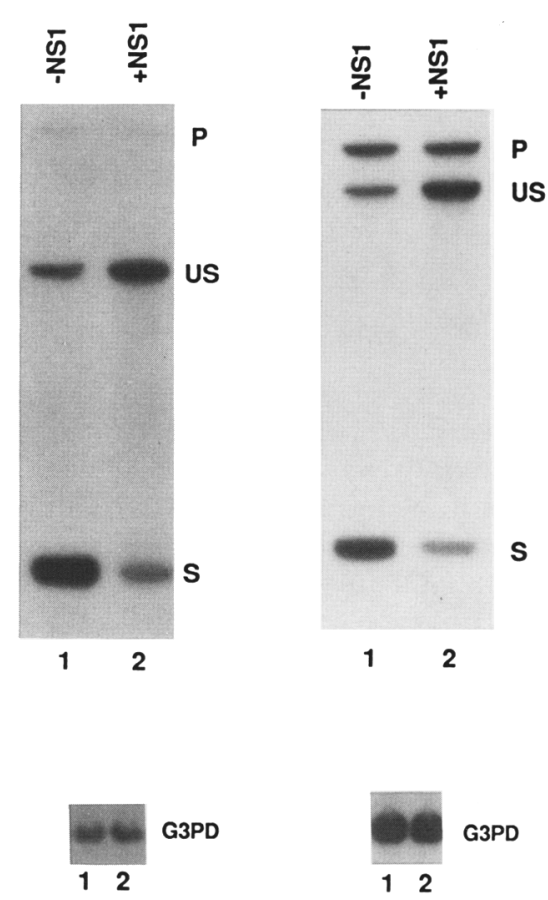

Figure 1. The NS1 protein inhibits the splicing of pre-mRNA in vivo. $(A)$ The pBC12 construct of the $\beta$-globin gene contains two exons and the intron under the control of the cytomegalovirus (CMV) promoter. Also shown here is the M13 single-stranded DNA template used for generating the 5 '-end labeled single-stranded probe specific for globin pre-mRNA. In an S1 nuclease assay this probe will differentiate between unspliced pre-mRNA and spliced mRNA, as shown. $(B) 293$ cells were cotransfected with $5 \mu g$ of the PBC12 plasmid encoding $\beta$-globin pre-mRNA and $10 \mu \mathrm{g}$ of either the PBCl2 plasmid encoding the NS1 protein (NS3ss) ( + NS1) or the PBC12 plasmid containing an NS1-coding sequence with two amber mutations (NS3ssdm) (-NS1). At 40 hr post-transfection, the cells were fractionated into nuclei and cytoplasm, and the nuclear $(\mathrm{N})$ and cytoplasmic $(\mathrm{C})$ RNAs were extracted and subjected to S1 analysis as described in Materials and methods. The protected fragments were resolved by gel electrophoresis, as shown (top). (US) Unspliced; (S) spliced; (P) probe. To monitor the amount and purity of the nuclear and cytoplasmic RNAs used in the S1 assay, the same amount of RNA samples used in the top panel was analyzed by Nothern blot analysis in which the blots were sequentially hybidized with an oligonucleotide specific for cellular G3PD and an oligonucleotide specific for 45S pre-rRNA (bottom). The 45S RNA and G3PD RNAs were found exclusively in their appropriate cellular fraction, and the amounts were comparable between samples. $(C)$ The same experiment as in $B$, except that total cellular RNA was collected. The total RNA samples were also probed with the G3PD-specific oligonucleotide. $(D)$ The pSTER-SV-AG plasmid was used as a target. This plasmid produces only SV40 large $T$, and not small $t$, pre-mRNA because of a branch site mutation. The total RNA samples were also probed with the G3PD-specific oligonucleotide.

the presence of the NS1 protein the globin pre-mRNA was not spliced and accumulated in the nucleus (Fig. 1B). When the amount of the NS1 protein-coding vector used in the transfection was lowered fourfold, the inhibitory effect on splicing still occurred (data not shown). In subsequent experiments total cellular RNA was analyzed (Fig. 1C,D). In the absence of the NS1 protein the ratio of unspliced to spliced globin mRNA was $1: 7$, whereas in the presence of the NS1 protein this ratio was reversed, to a ratio (unspliced to spliced) of 4:1 (Fig. 1C). Splicing inhibition was general, as the NS1 protein inhibited the splicing of other pre-mRNAs: SV40 early T mRNA (Fig. 1D), HIV tat pre-mRNA, and an adenovirus pre-mRNA (data not shown). Similar results were obtained in Cos cells (data not shown). The NS1 protein did not differ- entially affect the stability of unspliced and spliced $\mathrm{mR}$ NAs, as demonstrated by actinomycin D chase experiments (data not shown), confirming that the increase in the ratio of unspliced to spliced mRNA caused by the NS1 protein (Fig. 1) resulted from an inhibition of splicing.

The NS1 protein has two functional domains: an RNA-binding domain and an effector domain /Qian et al. 1994) (Fig. 2A). To determine whether these domains were required for splicing inhibition, we measured the splicing inhibitory activities of NS1 proteins containing mutations in these domains (Fig. 2B,C). All mutations in the effector domain rendered the NS1 protein inactive in inhibiting pre-mRNA splicing in vivo. Mutations in the RNA-binding domain (M2, M3, and M4) caused a loss of 
A

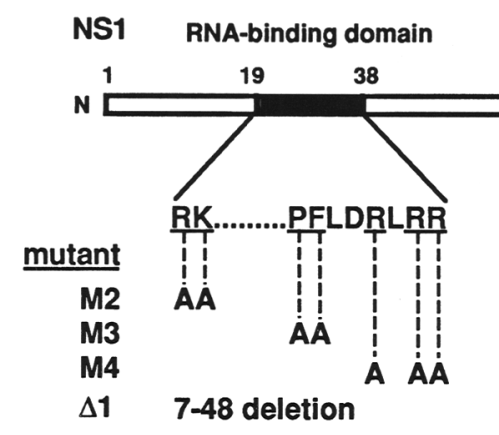

B

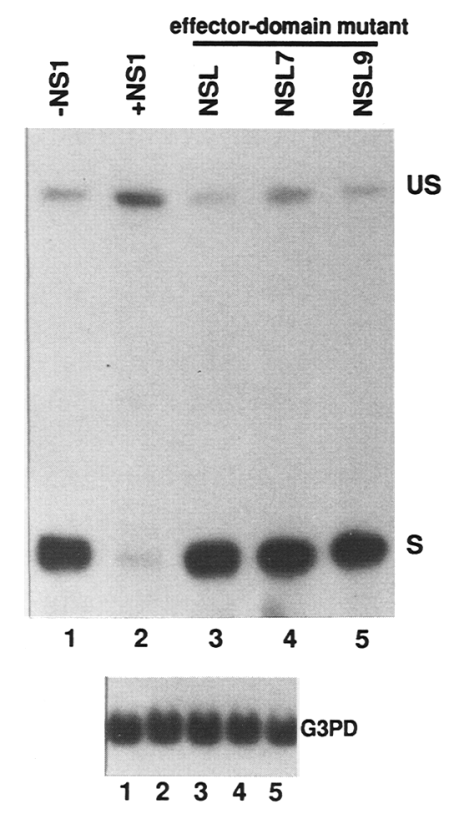

Effector domain

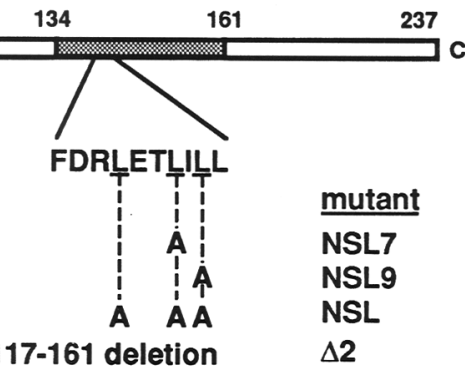

117-161 deletion

c

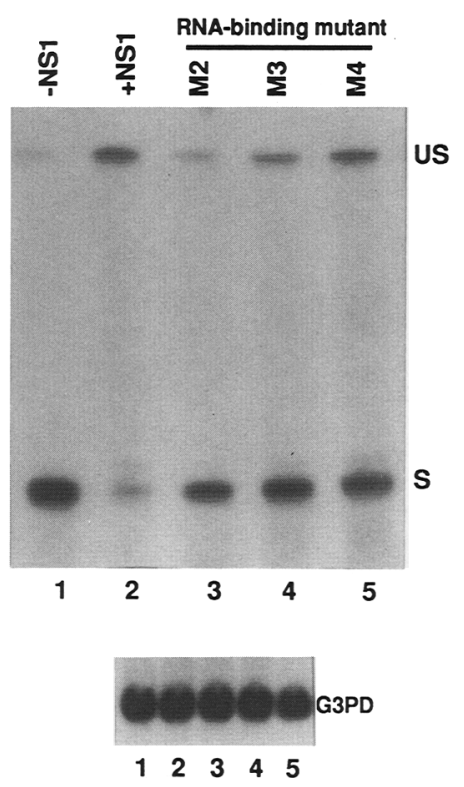

Figure 2. The effector and RNA-binding domains of the NS1 protein are required for the inhibition of splicing in vivo. $(A) \mathrm{De}$ scription of the NS1 protein mutants used in this and subsequent experiments. These mutants have been shown to lose the function of inhibiting the nuclear export of $\mathrm{mR}$ NAs (Qian et al. 1994). (B,C). 293 cells were cotransfected with $5 \mu \mathrm{g}$ of the $\mathrm{pBCl} 2$ plasmid encoding the $\beta$-globin pre-mRNA and $10 \mu \mathrm{g}$ of one of the following pBC12 plasmids: NS3ssdm (-NS1); NS3ss (+NS1); NS1; NSL7; NSL9; M2; M3; M4. At 40 hr post-transfection the total RNA of the cells was isolated and subjected to $\mathrm{Sl}$ analysis, and the protected fragments were resolved by gel electrophoresis. (US) Unspliced; (S) spliced. The RNA samples were subsequently probed with the G3PD-specific oligonucleotide as shown (bottom). most of the splicing inhibitory activity. As documented previously (Qian et al. 1994), the level of expression and the relative stability of these mutant proteins in transfected cells was comparable with those of the wild-type protein. Thus, these experiments indicate that the inhibition of pre-mRNA splicing in vivo by the NS1 protein requires both its effector and RNA-binding domains.

The NS1 protein has been shown to bind to poly(A) (Qiu and Krug 1994). However, a 3' poly(A) sequence in the pre-mRNA is not required for splicing inhibition by the NS1 protein. This was demonstrated by utilizing a globin pre-mRNA containing a histone $3^{\prime}$ end, that is, lacking a poly(A) sequence (data not shown). Other viral nuclear RNA-binding proteins, the HIV-1 Rev protein and the $\delta$ antigen of hepatitis $\delta$ virus, did not inhibit the splicing of globin pre-mRNA (data not shown).

\section{The NS1 protein inhibits pre-mRNA splicing in vitro}

To obtain definitive evidence that the NSI protein acts directly on splicing, we tested this protein in in vitro splicing reactions. Increasing amounts of a glutathione $S$-transferase (GST)-NS1 fusion protein effectively inhibited the in vitro splicing of a globin pre-mRNA, whereas the GST protein alone had no effect (Fig. 3). In the presence of $0.50 \mu \mathrm{g}$ of the GST-NS1 fusion protein, the spliced mRNA product was almost totally absent, whereas some of the two splicing intermediates, the $5^{\prime}$ exon and the intron lariat $-3^{\prime}$ exon, were produced. When the amount of the GST-NS1 fusion protein was increased to $1.0 \mu \mathrm{g}$, the splicing intermediates decreased in amount, though some still remained, and more of the pre-mRNA precursor accumulated. Time-course experiments indicated that splicing intermediates were produced in the presence of the GST-NS1 protein primarily, if not entirely, at early times of the splicing reaction (data not shown).

GST-NS1 fusion proteins containing mutations in the RNA-binding domain of the NS1 protein did not inhibit the splicing of globin pre-mRNA (Fig. 4A), indicating that the RNA-binding domain is required for the inhibition of pre-mRNA splicing in vitro, as is the case in vivo. In contrast to the situation in vivo, a GST-NS1 fusion 


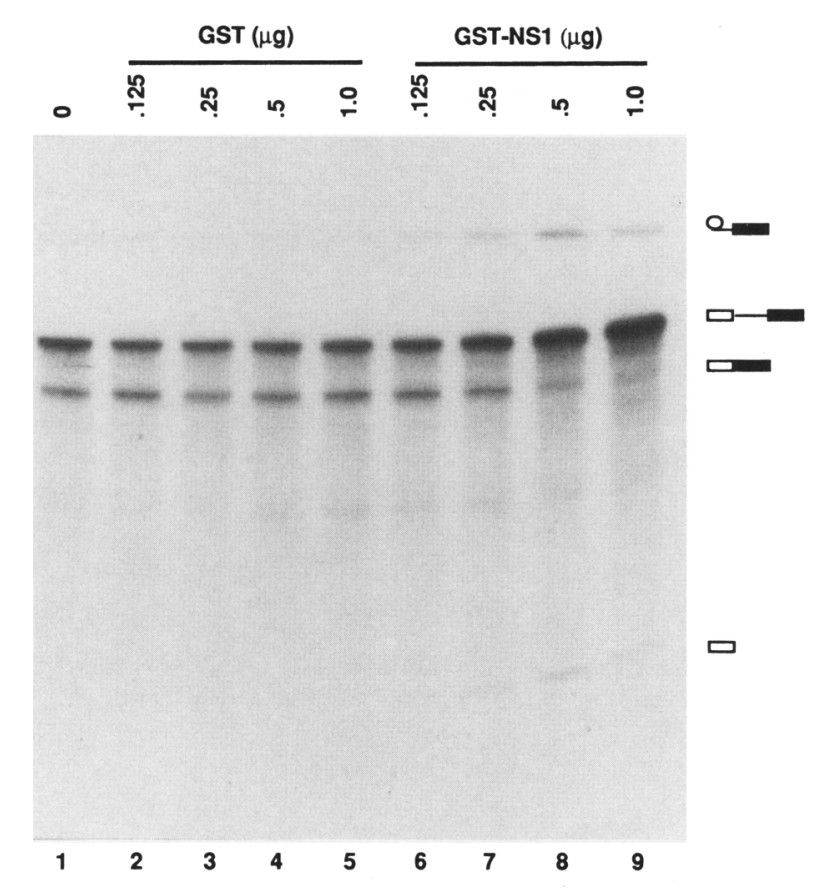

Figure 3. The NS1 protein inhibits pre-mRNA splicing in vitro. ${ }^{32} \mathrm{P}$-Labeled $\beta$-globin pre-mRNA was incubated for $2 \mathrm{hr}$ at $30^{\circ} \mathrm{C}$ with $\mathrm{HeLa}$ cell nuclear extract under splicing conditions in the absence (0) or presence of the indicated amounts of the GST protein or GST-NS1 fusion protein. The RNA products were analyzed by gel electrophoresis. The identities of the premRNA and splicing products, which have been established previously (Furneaux et al. 1985; Perkins et al. 1986; Agris et al. 1989; Krainer et al. 1990), are indicated schematically: $\square$ and $\square$ correspond to the 5 ' and 3 ' exons, respectively; thin lines correspond to the intron, which is converted to a lariat form during splicing.

protein containing three leucine $\rightarrow$ alanine mutations in the effector domain (NSL) effectively inhibited the splicing of the globin pre-mRNA (Fig. 4B). The same result was obtained using the NSL protein cleaved from the GST fusion protein (data not shown). Thus, only the RNA-binding domain was required for splicing inhibition in vitro.

To address possible nonspecific inhibitory effects caused by RNA-binding proteins in general, we tested the effects of other RNA-binding proteins. In particular, we added increasing amounts of a poly(A)-binding protein, a fusion protein consisting of GST linked to two ribonucleotide (RNP) domains of the human poly(A)binding protein (PABP) (Görlarch et al. 1994). This protein, which has a $K_{\mathrm{d}}$ for poly(A) similar to that of the NS1 protein for poly(A) (data not shown), did not inhibit the in vitro splicing of adenovirus pre-mRNA (Fig. $4 \mathrm{C}$ ). Consequently, splicing inhibition was not caused by a protein that binds to poly(A). In addition, GST-Rev and glyceraldehyde-3-phosphate dehydrogenase (G3PD) (Singh et al. 1993) did not inhibit globin pre-mRNA splicing (data not shown). It has been shown previously that the HIV Rev protein does not inhibit the splicing of globin pre-mRNA lacking the RRE that is recognized by the Rev protein (Kjems et al. 1991).

\section{The NS1 protein is associated with spliceosomes}

Because the first chemical step in splicing occurred to a certain extent in the presence of the GST-NS1 protein, it was likely that spliceosome formation also occurred to a great extent. To establish whether this was the case, we determined the time course of spliceosome formation using native gel electrophoresis (Fig. 5). In the control reaction, in the presence of $0.75 \mu \mathrm{g}$ of the GST protein (lanes 1-4), a large proportion of the adenoviral premRNA became associated with a complex (complex B) that migrated slower than the initial complex (complex A). As expected for spliceosomes, the formation of complex B was ATP-dependent, and this complex contained at least U5 and U6 small nuclear RNAs (snRNAs) as detected by Northern analysis (data not shown). Others have shown that the largest, or slowest migrating, species in native gels are spliceosomes containing at least the U2, U5, and U6 small nuclear RNPs (snRNPs) (Konarska and Sharp 1987). Under our experimental conditions, spliceosomes that contained splicing intermediates were not resolved from spliceosomes that lacked splicing intermediates. In the presence of the GST-NS1 protein $(0.75 \mu \mathrm{g})$ complex B was formed with essentially the same time course and efficiency as in the control reaction (lanes 5-8), indicating that this protein did not significantly affect the formation of these spliceosomes. As shown below, at least some of the spliceosomes formed in the presence of the GST-NS1 protein contained splicing intermediates.

To determine whether the NS1 protein was associated with the spliceosomes that were formed, a splicing reaction containing the GST-NS1 protein and a labeled adenovirus pre-mRNA was incubated for $1 \mathrm{hr}$ at $30^{\circ} \mathrm{C}$, and the reaction mixture was then subjected to affinity selection on glutathione-agarose beads. If the GST-NS1 protein became associated with spliceosomes, the affinity selection should yield the pre-mRNA, splicing intermediates, and the snRNAs that participate in splicing. As shown in Fig. 6A (lane 6), a large fraction of the premRNA and splicing intermediates in the reaction was selected by glutathione-agarose beads. It should be noted that the portion of the reaction mixture $(5 \mu \mathrm{l})$ not subjected to the affinity selection (Fig. 6A, lane 2) was incubated for $2 \mathrm{hr}$ at $30^{\circ} \mathrm{C}$, or $1 \mathrm{hr}$ longer than the affinityselected portion of the reaction mixture (Fig. 6A, lane 6), thereby explaining the difference in the ratio of premRNA to splicing intermediates between these two portions of the reaction mixture. In addition, as detected using Northern analysis by digoxigenin-labeled riboprobes, the U1, U2, U4, U5, and U6 snRNAs were also selected by glutathione-agarose beads (WT, Fig. 6B, lane 3). This indicates that the GST-NS1 protein was associated with spliceosomes and, further, that these spliceosomes contained splicing intermediates. On the basis of the same criteria, a GST-NS1 protein containing a deletion of the effector domain of the NS1 protein $(\Delta 2)$ was 
A

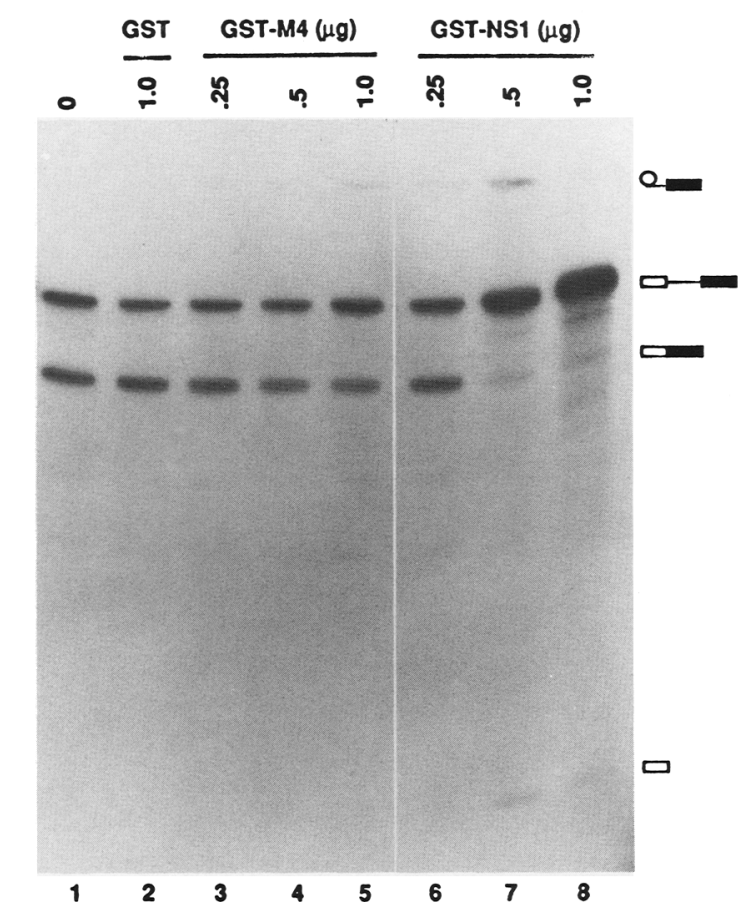

B

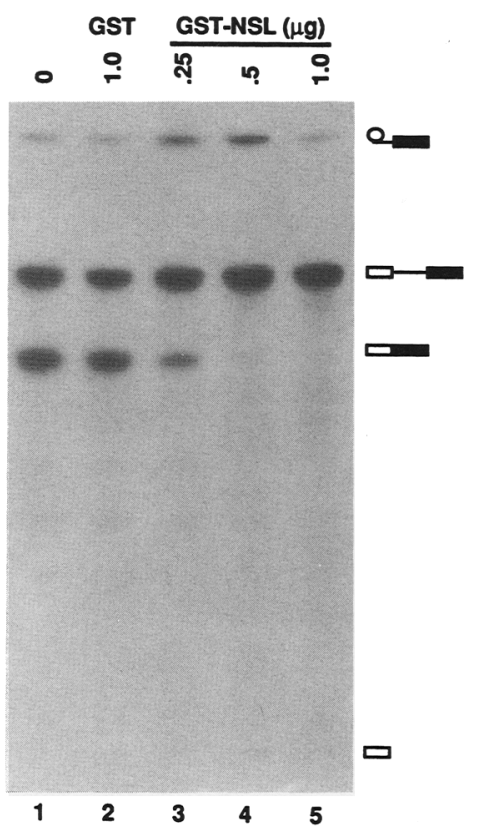

C

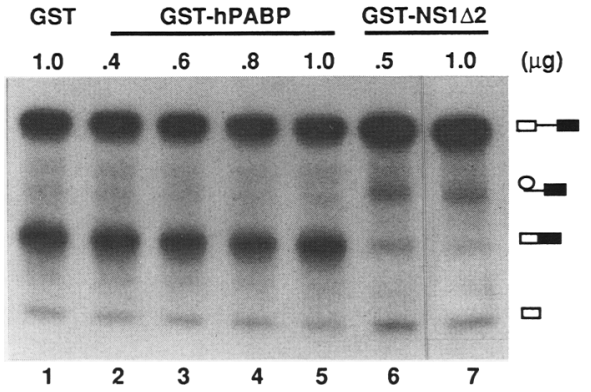

Figure 4. The RNA-binding domain is sufficient for splicing inhibition in vitro. $(A, B)^{32} \mathrm{P}$-Labeled $\beta$-globin pre-mRNA was incubated for $2 \mathrm{hr}$ at $30^{\circ} \mathrm{C}$ with $\mathrm{HeLa}$ cell nuclear extract under splicing conditions in the absence $(0)$ or presence of the indicated amount of the GST protein, the GST-NS1 protein, the GST-M4 (RNAbinding mutant) fusion protein $(A)$, or the GST-NSL (effector domain mutant) fusion protein $(B)$. The RNA products were analyzed by electrophoresis on $11 \%$ polyacrylamide gels. $(C)$ GST-NS1 $\Delta 2$ (effector deletion mutant) was used in the same assay. The ${ }^{32} \mathrm{P}$-labeled adenovinus pre-mRNA was incubated for $2 \mathrm{hr}$ at $30^{\circ} \mathrm{C}$ under splicing conditions in the presence of the indicated amount of the GST protein, the GST-hPABP, or the GST-NS1 22 (effector deletion mutant). associated with spliceosomes (Fig. 6A, lane 7; Fig. 6B, lane 4). In contrast, the GST protein alone (Fig. 6A, lane 5; Fig. 6B, lane 2) or the GST-NS1 protein with an RNAbinding domain deletion $(\Delta 1)$ (Fig. 6A, lane 8; Fig. 6B, lane 5) did not associate with spliceosomes, as little or no pre-mRNA and splicing intermediates and only a background amount of the U1 and U2 snRNAs were selected by the glutathione-agarose beads.

To verify these conclusions, a control reaction was carried out in which spliceosome formation was abrogated by the omission of ATP and an ATP-generating system from the reaction mixture (Fig. 6C,D). Under these conditions, affinity selection of the splicing reactions did not yield the pre-mRNA and splicing intermediates, and only the same background amount of the U1 and U2 snRNAs was found in the reactions containing any of the four proteins. This verifies that the GST-NS1 protein associates with spliceosomes in the splicing reaction. In addition, using various levels of the NS1 pro- tein, it was shown that there was a direct correlation between the amount of binding of the NS1 protein to spliceosomes and the extent of the splicing inhibition observed (data not shown).

\section{The NS1 protein is associated with U6 snRNA in the uninfected cell splicing extract and in influenza virus-infected cells}

As shown above, the RNA-binding domain is essential for the NS1 protein to associate with spliceosomes and inhibit splicing. This suggests that the NS1 protein interacts with an snRNA on the spliceosome. In vitro binding-selection experiments established that the NS1 protein specifically binds to U6 snRNA /Y. Qiu and R.M. Krug, in prep.). In the present study we show that the NS1 protein specifically associates with U6 snRNA when added to heat-treated HeLa nuclear splicing extracts from uninfected cells and that the endogenous U6 


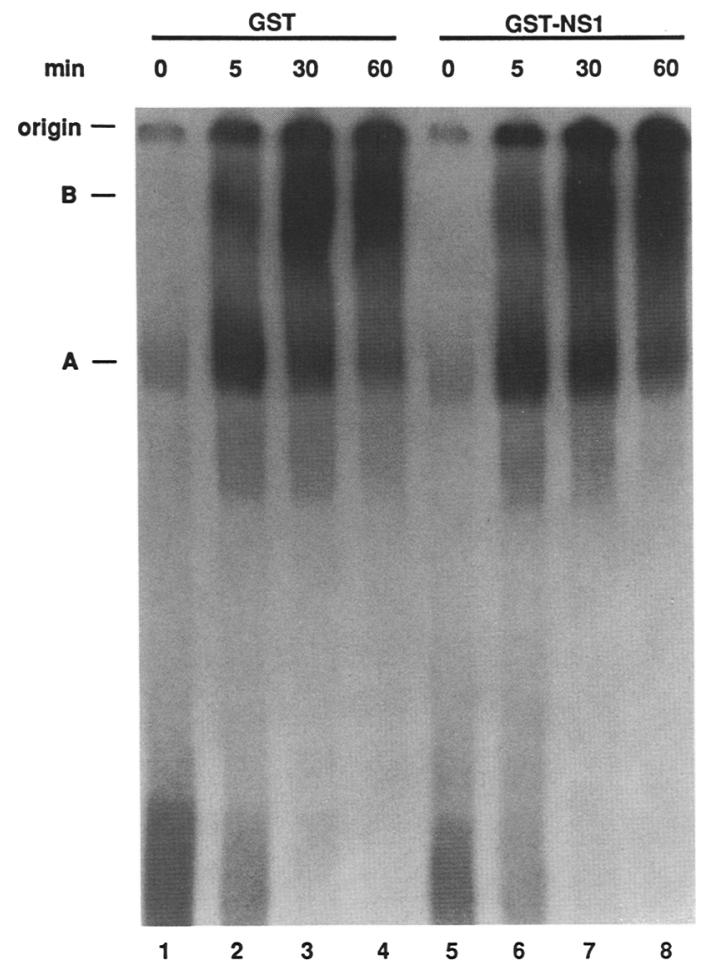

Figure 5. Spliceosome formation in the presence and absence of the NS1 protein. Splicing reactions $(60 \mu l)$ containing HeLa nuclear extract and $3 \times 10^{5} \mathrm{cpm}$ of ${ }^{32} \mathrm{P}$-labeled adenovirus premRNA were carried out in the presence of $2.25 \mu \mathrm{g}$ of either GST or GST-NS1 protein. At the times indicated, $10-\mu l$ aliquots were withdrawn. Ten microliters of $1 \mathrm{mg} / \mathrm{ml}$ of heparin was added to the aliquots, and the mixtures were incubated for 10 min on ice. Samples were then loaded onto a $4 \%(80: 1)$ polyacrylamide gel containing $50 \mathrm{~mm}$ Tris-glycine. The electrophoresis was carried out for $7 \mathrm{hr}$ at the maximum power of $4 \mathrm{~W}$. (A) A complex; (B) B complex.

snRNA in influenza virus-infected cells is associated with the NS1 protein.

A nuclear splicing extract from uninfected HeLa cells was heated at $65^{\circ} \mathrm{C}$ for $5 \mathrm{~min}$ prior to the splicing reaction to inactivate the factors needed for spliceosome formation. The GST-NS1 protein and the labeled adenovirus pre-mRNA were added to the preheated extract, and after a $1-\mathrm{hr}$ incubation at $30^{\circ} \mathrm{C}$ the reaction mixture was subjected to affinity selection on glutathione-agarose beads (Fig. 7A). None of the labeled pre-mRNA was selected (data not shown), verifying that spliceosome formation did not occur. In the reactions containing the GST-NS1 (wild type) and GST-NS1 2 (effector domain deletion/ proteins, that is, the two proteins that associate with spliceosomes in a standard splicing reaction, one snRNA, U6 snRNA, was specifically selected by the glutathione-agarose beads (lanes 3,4 ). In contrast, U6 snRNA was not selected from a splicing reaction containing the GST-NS1 1 (RNA-binding domain deletion) protein (lane 5).

The specific binding of the NS1 protein to U6 snRNA provides an approach for relating the splicing results ob- tained in the transfection and in vitro splicing assays to events in influenza virus-infected cells. As shown by quantitative Western blot analysis, the amount of the NS1 protein per cell in transfected cells was comparable with that in influenza virus-infected cells (data not shown). To determine whether the NS1 protein was associated with U6 snRNA in influenza virus-infected cells, mock-infected and influenza virus-infected cells $\mid 3$ hr postinfection) were disrupted by sonication, and the resulting extracts were immunoprecipitated with an anti-NS1 antiserum or a control serum. The RNAs in the precipitate were resolved by gel electrophoresis, and the spliceosomal U snRNAs were assayed by Northern analysis (Fig. 7B). U6 snRNA was specifically associated with the NS1 protein in infected cells (lane 2). In contrast, the other U snRNAs were not specifically precipitated by the anti-NSl antiserum.

\section{The splicing of the viral ns1 mRNA is resistant to inhibition by the NS1 protein}

All of the pre-mRNAs that we have utilized in the experiments described above were not encoded by the influenza virus genome. The splicing of all of these noninfluenza pre-mRNAs was inhibited by the NS1 protein. We determined whether the NS1 protein also inhibited the splicing of the two influenza virus mRNAs that undergo splicing: the $m 1$ mRNA /encoding the matrix protein) and ns1 mRNA (encoding the NS1 protein itself). In transfection experiments the $m 1 \mathrm{mRNA}$ is spliced to form $m 3$ mRNA, utilizing one of two alternative $5^{\prime}$ splice sites (Lamb and Lai 1984; Alonso-Caplen et al. 1992). We mutated this $5^{\prime}$ splice site so that the other $5^{\prime}$ splice site was used, thereby forming $m 2$ mRNA, which encodes the M2 integral membrane protein. In transfection experiments the NS1 protein effectively inhibited the splicing of the $m 1$ mRNA (Fig. 8A), similar to the inhibition seen with other pre-mRNAs. The splicing of $m 1$ mRNA to form $m 3$ mRNA was also inhibited (data not shown).

To examine the effect of the NS1 protein on the splicing of $n s 1$ mRNA itself, it was necessary to introduce three amber mutations into the target $n s 1$ mRNA so that it did not encode functional NS1 and NS2 proteins (Alonso-Caplen et al. 1992), and as usual the NS1 protein was provided in trans by an unspliceable ns1 mRNA. In contrast to all the other pre-mRNAs tested, the in vivo splicing of viral ns1 mRNA to form ns2 mRNA was not inhibited by the NS1 protein (Fig. 8B). To establish whether this lack of inhibition was attributable to cis sequences in the target ns1 mRNA, the plasmid encoding globin pre-mRNA was cotransfected into the cells with the plasmids specifying the NS1 protein and the ns1 mRNA target (Fig. 8C). In such cells the NS1 protein acted on the splicing of the globin pre-mRNA in a different way than on ns1 mRNA splicing. Globin premRNA splicing was effectively inhibited, whereas $n s 1$ mRNA splicing was not affected. Hence, the resistance to splicing inhibition was attributable to sequence(s) in ns1 mRNA itself, and the ability of the NS1 protein to 
A +ATP

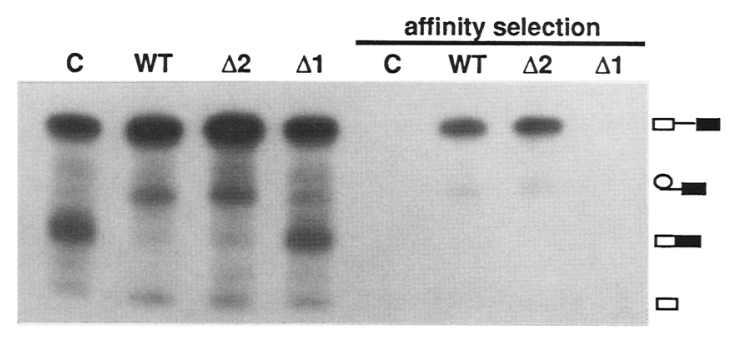

C. -ATP

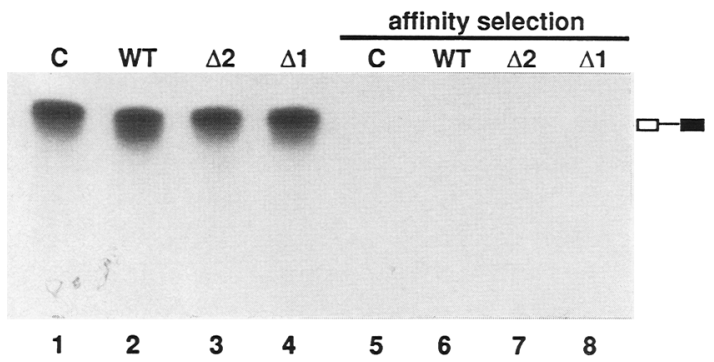

B +ATP

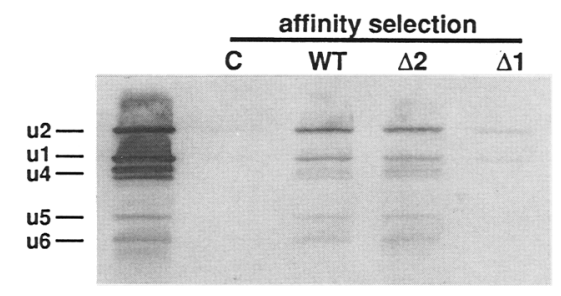

D. -ATP

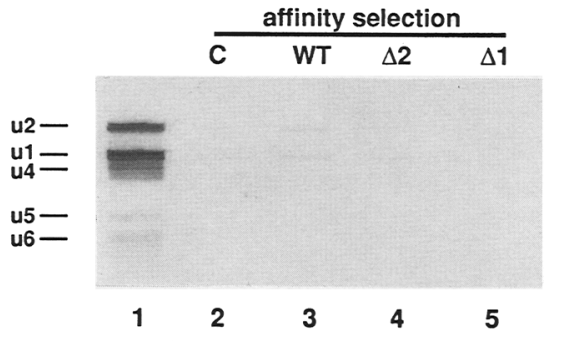

Figure 6. The NS1 protein is associated with spliceosomes. $(A)^{32} \mathrm{P}$-Labeled adenovirus pre-mRNA was incubated for 1 hour at $30^{\circ} \mathrm{C}$ with HeLa cell nuclear extract under splicing conditions ( + ATP) in a final volume of $35 \mu$ l in the presence of $1.3 \mu \mathrm{g}$ of the GST protein (C, control), the GST-NS1 fusion protein (WT, wild type), the GST-NS1 fusion protein containing a deletion in the NS1 effector domain $(\Delta 2)$, the GST-NSI fusion protein containing a deletion in the NSl RNA-binding domain $(\Delta 1)$. Most (30 $\mu$ l) of each reaction mixture was subjected to affinity selection on glutathione-agarose beads as described in Materials and methods. The labeled RNA bound to the beads was analyzed by electrophoresis on a 7\% polyacrylamide gel (lanes $5-8)$. The remaining $5 \mu l$ of the reaction mixture that was not used for affinity selection was incubated for an additional hour at $30^{\circ} \mathrm{C}$, and the splicing products were analyzed by gel electrophoresis (lanes 1-4). (B) After autoradiography of the gel, lanes 4-8 from $A$ were electroblotted onto a Nytran membrane and probed with digoxigenin-containing riboprobes specific for the U1, U2, U4, U5, and U6 snRNAs as described in Materials and methods. The identity of the individual snRNA bands was verified by using individual riboprobes in separate assays. (C) The ATP and ATPgenerating system (creatine phosphate and creatine phosphokinase) were omitted from the splicing reactions. (Lanes 1-4) Splicing products after $2 \mathrm{hr}$ incubation. (Lanes 5-8) Labeled RNAs after affinity selection on glutathione-agarose beads. $(D)$ U snRNAs detected on a Nytran membrane after electroblotting lanes $4-8$ from $C$. Lanes 1 in $B$ and $C$ contain RNA extracted from $0.75 \mu l$ of HeLa nuclear extract $(20 \mathrm{mg}$ protein $/ \mathrm{ml}$ ).

inhibit the splicing of another pre-mRNA, globin premRNA, was not affected by the presence of the ns1 and ns2 mRNAs.

\section{Discussion}

The influenza virus NS1 protein is unique in that it inhibits two different steps in the processing of mRNA: nuclear export of poly(A)-containing mRNAs, and premRNA splicing (Alonso-Caplen et al. 1992; Fortes et al. 1994; Qian et al. 1994; Qui and Krug 1994; this study). In addition, as shown here, the mode by which the NS1 protein inhibits splicing is novel. Other proteins that regulate pre-mRNA splicing apparently operate by inhibiting or enhancing the formation of spliceosomes at specific splice site(s) (Baker 1989; Green 1989; Inoue et al. 1990; Bell et al. 1991; Tian and Maniatis 1992). In contrast, the NS1 protein allows the pre-mRNA to associate with the U1, U2, U4, U5, and U6 snRNPs to form spliceosomes but then remains associated with these spliceosomes to inhibit the catalytic steps of splicing that are normally carried out by spliceosomal components.

Spliceosome formation was assayed in two ways. First, native gel electrophoresis indicated that spliceosomes formed with essentially the same efficiency in the presence and absence of the NSl protein. In addition, affinity selection of GST-NS1 from splicing extracts established that the NSl protein was associated with spliceosomes that contained splicing intermediates. These experiments are most consistent with the NS1 protein inhibiting splicing after the formation of spliceosomes containing splicing intermediates, although we cannot exclude the possibility that there is some effect on U RNA interactions that occur at later stages of spliceosome formation prior to the synthesis of splicing intermediates. It is probably significant that the synthesis of splicing intermediates occurs primarily, if not entirely, at early times in the presence of the NS1 protein. This is consistent with the hypothesis that the NS1 protein freezes the splicing catalytic machinery after it has completed the initial round of the first step, so that neither the second step of splicing nor subsequent rounds of the first step can occur.

The RNA-binding domain of the NS1 protein is required for the inhibition of pre-mRNA splicing in vivo and in vitro. Whereas the NSI protein binds to a poly(A) 
A pre-heated extract

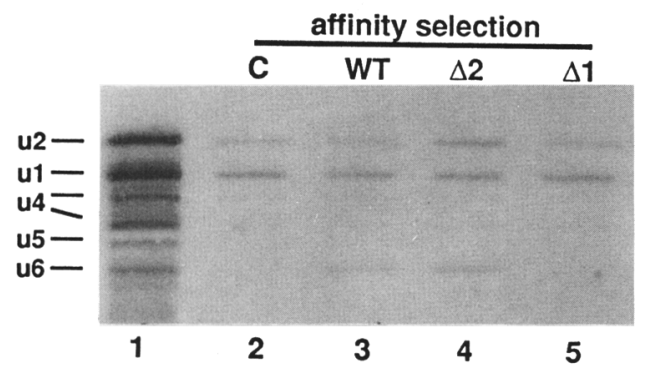

$B$ infected cell

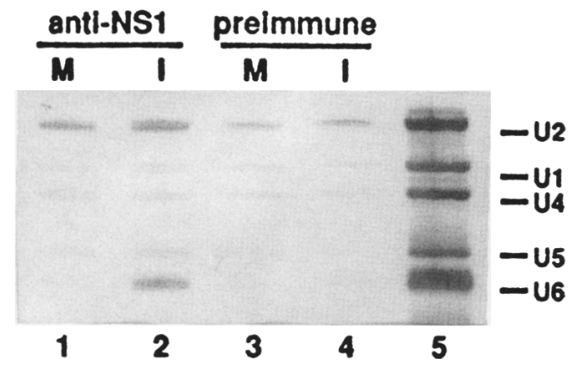

Figure 7. NS1 protein interacts with U6 snRNA in uninfected cell splicing extracts and in influenza virus-infected cells. $(A) \mathrm{A}$ HeLa cell nuclear extract was inactivated by preheating it at $65^{\circ} \mathrm{C}$ for $5 \mathrm{~min}$ before adding it to a splicing reaction containing ${ }^{32} \mathrm{P}$-labeled adenovirus pre-mRNA in a final volume of $35 \mu \mathrm{l}$. The subsequent experimental procedure was the same as described in the legend to Fig. 6. After affinity selection on glutathione-agarose beads, the RNAs were extracted and analyzed on a $7 \%$ urea-polyacrylamide gel: The affinity selection did not bring down any pre-mRNA (data not shown). After the gel was electroblotted onto a Nytran membrane, U snRNAs were detected using digoxigenin-labeled U1, U2, U4, U5, and U6 sRNA probes. (Lane 1) The $U$ snRNAs extracted from $0.75 \mu$ l of HeLa cell nuclear extract $(20 \mathrm{mg}$ of protein/ml). (C) GST protein; (WT) GST-NSl; $(\Delta 2)$ GST-NS1 $\Delta 2$ (effector domain deletion mutant); $(\Delta 1)$ GST-NS1 $\Delta 1$ (RNA-binding domain mutant deletion). (B) 293 cells (one 60-mm dish) infected with influenza virus Udorn $\mathrm{A} / 72$ strain or mock-infected for $3 \mathrm{hr}$ at $37^{\circ} \mathrm{C}$ were subjected to immunoprecipitation as described in Materials and methods. RNAs were extracted and electrophoresed on a $5 \%$ urea-polyacrylamide gel. After blotting onto Nytran membrane, U snRNAs were detected as described above. In lane 5, RNAs extracted from $25 \mu$ l out of $500 \mu$ l of cell extract from one $60-\mathrm{mm}$ dish were loaded as a standard. (M) mock infection; (I) infection.

sequence when it inhibits the nuclear export of mRNAs (Qiu and Krug 1994), it is undoubtedly interacting with a different sequence-a sequence in U6 snRNA-when it inhibits splicing. The inhibition of splicing in vivo and in vitro occurs when the pre-mRNA lacks poly(A). No poly(A) sequences were present in the in vitro splicing reactions, and the addition of a cellular poly(A)-binding protein had no effect on in vitro splicing. Experiments in which the NS1 protein selected its specific binding site from a random collection of oligoribonucleotides estab- lished that the NS1 protein specifically binds to a sequence (nucleotides 87-97) at the $3^{\prime}$ end of U6 snRNA (Y. Qiu and R.M. Krug, in prep.). In addition, in the present study we showed that when splicing extracts were preheated to inactivate splicing factors, U6 snRNA was the only specific snRNA that interacted with the NS1 protein. Preheating probably facilitated this interaction by dissociating U6 snRNA from U4 snRNA and also prevented the association of $U 6$ and other $U$ snRNAs with the spliceosomes so that U6 snRNA was the only snRNA that was affinity selected in association with the NS1 protein.

The most likely interpretation of our results /this study; Y. Qiu and R.M. Krug, in prep.) is that the NS1 protein inhibits splicing by binding to U6 snRNA molecules on spliceosomes. The extent of inhibition was directly correlated with the binding of the NS1 protein to spliceosomes. Presumably, effective inhibition requires that the NS1 protein binds to a sufficient number of spliceosomal U6 snRNA molecules to inactivate the majority of the spliceosome population. Clearly, it will be of great interest to determine how the binding of the NS1 protein to the sequence at the $3^{\prime}$ end of U6 snRNA /this study; Y. Qiu and R.M. Krug, in prep.) affects the interaction of U6 snRNA with the other spliceosomal U snRNAs and with the pre-mRNA and splicing intermediates (Datta and Weiner 1991; Wu and Manley 1991; Madhani and Guthrie 1992; Lesser and Guthrie 1993; Sontheimer and Steitz 1993; Wolff and Bindereif 1993).

The NS1 protein, which is localized in the nucleus, has two major functional domains: an RNA-binding domain and an effector domain that presumably interacts with host nuclear proteins (Qian et al. 1994). Both domains are required for the inhibition of the nuclear export of mRNA. The RNA-binding domain is also required for the inhibition of splicing both in vivo and in vitro. In contrast, the effector domain is required for the inhibition of splicing only in vivo but not in vitro. Presumably, one role of the effector domain in the cell is to interact with nuclear targets that position the NS1 protein at an appropriate intranuclear localization so that this protein can inhibit splicing. In fact, mutations in the effector domain change the intranuclear/intracellular distribution of the NS1 protein (Qian et al. 1994).

The NS1 protein is selective in that it does not inhibit the splicing of one of the only two influenza viral $\mathrm{mR}$ NAs that undergo splicing; specifically, ns1 mRNA, the very mRNA that encodes the NS1 protein itself. This resistance is attributable to sequences in ns1 mRNA, because in the same cells in which ns1 mRNA splicing was not affected by the NS1 protein, the splicing of a globin pre-mRNA was effectively inhibited. In addition, this result indicates that the viral $n s 1$ and $n s 2$ mRNAs do not affect the ability of the NS1 protein to inhibit the splicing of other pre-mRNAs in the same cells. Therefore, it is not likely that the ns1 and ns2 mRNAs titrate out the NSl protein. The key question is, How do these ns1 mRNA sequences confer resistance to the NS1 protein, which inhibits catalytic step(s) of splicing that are presumably common to all other pre-mRNAs? Do these 

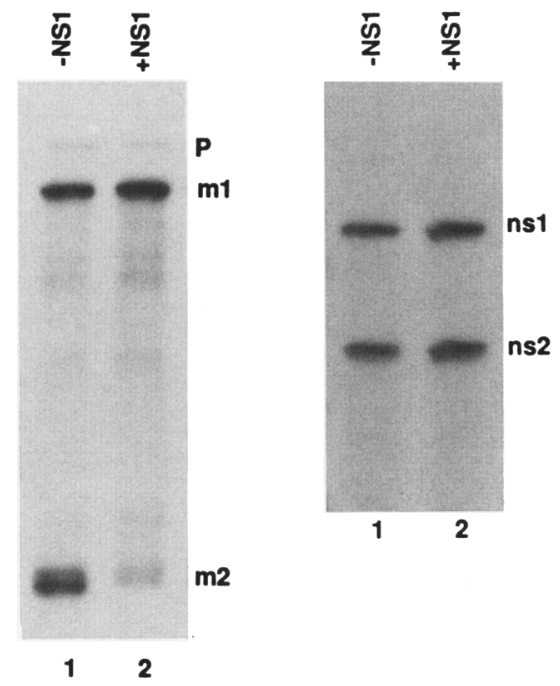

m2

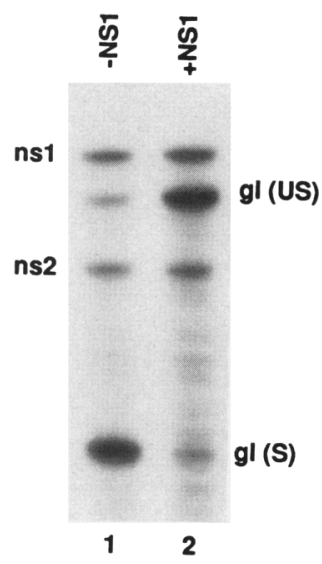

Figure 8. The splicing of influenza virus ns1 mRNA is resistant to inhibition by the NS1 protein. 293 cells were cotransfected with $10 \mu \mathrm{g}$ of the PBC12 plasmid either encoding no NS1 protein (-NS1, NS3ssdm), or encoding the NS1 protein (+NS1, NS3ss); and $5 \mu \mathrm{g}$ of the PBC12 plasmid either encoding a $m 1 \mathrm{mRNA}$ with a mutation in the $5^{\prime}$ proximal $5^{\prime}$ splice site $|A|$, or encoding an $n s 1$ mRNA (NSlam3) with two amber mutations in the NS1 reading frame and one amber mutation in the NS2 reading frame $(B)$. In $C, 5 \mu \mathrm{g}$ of both the PBC12-NS1 am 3 and the $\mathrm{PBC} 12 \beta$-globin plasmids were transfected in the absence and presence of the NS1 protein. At $40 \mathrm{hr}$ after transfection the total RNA of the cells was subjected to $S 1$ nuclease analysis with probes specific for $m 1$ and $m 2$ mRNAs $(A)$, ns1 and ns2 mRNA $(B)$ or ns1 and ns2 mRNA and $\beta$-globin mRNA $|C|$. The protected fragments were resolved by gel electrophoresis. (U) Unspliced; $|S|$ spliced. ns1 mRNA sequences supply some catalytic function(s) in cis so that some trans-catalytic function(s) provided by spliceosomal snRNAs are not required?

The specific binding of the NS1 protein to U6 snRNA allowed us to directly relate the results obtained in the transfection and in vitro splicing assays described here to events that occur in influenza virus-infected cells. In infected cells host-cell polymerase II transcripts are degraded in the nucleus, due at least in part to the cleavage of their $5^{\prime}$ ends by the viral cap-dependent endonuclease (Katze and Krug 1984; Krug et al. 1989). Against this background of degradation, it has not been possible to make a meaningful examination of the state of splicing of host pre-mRNAs in infected cells. As an alternative, we demonstrated that the NS1 protein synthesized in infected cells is specifically associated with endogenous U6 snRNA molecules. Immunoprecipitation of the NS1 protein from extracts obtained from infected cells specifically brought down the endogenous U6 snRNA and no other spliceosomal U snRNAs. A likely explanation for the absence of the other spliceosomal snRNAs from the NS1 protein immunoprecipitate is that during the preparation of the infected cell extracts, spliceosomes were disrupted and so was the association of other snRNAs (e.g., U4 or U2 snRNA) with U6 snRNA. This specific NS1 protein-U6 snRNA interaction in infected cells strongly suggests that the NS1 protein inhibits splicing in infected cells.

The present results lead to a modification of our hypothesis concerning the role of the NS1 protein during influenza virus infection (Qiu and Krug 1994). Because little or no spliced cellular mRNAs would be generated in infected cells (present study), the NS1 protein-mediated inhibition of nuclear export of poly(A)-containing mRNAs (Qiu and Krug 1994) is most likely directed against viral mRNAs, most of which are not generated by splicing. The NS1 protein would thus be responsible for regulating the early-to-late switch in viral protein synthesis by retaining the late viral mRNAs in the nucleus until the appropriate time for their expression. As discussed previously (Qiu and Krug 1994), it is likely that the NSI protein loses function at some point during infection as the result of a post-translational modification such as phosphorylation. The inhibition of pre-mRNA splicing by the NS1 protein would serve a different function. By allowing cellular pre-mRNAs to form spliceosomes but inhibiting most of the subsequent catalytic steps of splicing, the NS1 protein would sequester cellular pre-mRNAs to discrete sites in the nucleus, where these pre-mRNAs would then be accessible to the viral cap-dependent endonuclease for the generation of the capped primers that are needed for viral mRNA synthesis (Plotch et al. 1981; Krug et al. 1989). Further experiments are needed to prove several aspects of this model and to ascertain the reason for the NS1 protein-mediated inhibition of the splicing of the viral m1 mRNA but not that of the viral ns1 mRNA.

\section{Materials and methods}

\section{Transfection and S1 nuclease analysis}

The $\mathrm{pBC} 12$ plasmids containing the NSl gene used in the transfection experiments have been described previously (AlonsoCaplen et al. 1992). The NS1 protein was expressed using an NS1 gene containing a $3^{\prime}$ splice site mutation (NS3ss); the control plasmid (NS3ssdm) contained two amber mutations in the NS1 protein reading frame. The splicing of ns1 mRNA was assayed using the NSam3 gene, which contains wild-type splice sites and two amber mutations in the NS1 protein reading frame and one amber mutation in the NS2 protein reading frame. A $\beta$-globin minigene (Krainer and Maniatis 1984) was blunt-end ligated into the $\mathrm{pBC} 12$ vector. pSTER-SV-AG was kindly provided by James Manley (Columbia University, NY). 
Transfection was carried out as described previously (AlonsoCaplen et al. 1992). Cells were collected at $40 \mathrm{hr}$ post-transfection. Where indicated, cells were fractionated into nucleus and cytoplasm as described previously, using $45 \mathrm{~S}$ and $18 \mathrm{~S}$ rRNAs as markers for the purity of the fractions. Otherwise, unfractionated cells were used. RNA was extracted using the guanidinium isothiocyanate method (Chomcynski and Sacchi 1987). The extracted RNAs were assayed for the amounts of specific RNAs by S1 nuclease protection using specific $5^{\prime}$ end-labeled singlestranded DNA probes.

The M13 template for the globin-specific probe was constructed by inserting a HindIII-BamHI fragment containing exon 2 and part of the intron into the HindIII-BamHI site of M13mp9. For the construction of a SV40 specific singlestranded DNA template, the EcoRI-PstI fragment was isolated from PSTER-SV-AG. This fragment was digested with HindIII to yield a 1169-bp HindIII fragment that contains exon 2 and part of the intron. This fragment was cloned into the HindIII site of the M13mp19 vector. Oligonucleotides complementary to the sequence of the exon 2 of globin or SV40T were kinased at the $5^{\prime}$ end with $\left[\gamma^{-32} \mathrm{P}\right] \mathrm{ATP}$ and were annealed to the globin or SV40 single-stranded M13 DNA template. After primer extension using the Klenow fragment, the double stranded DNA was cleaved at the AvaI restriction site in M13. The double-stranded DNA was denatured and electrophoresed on an alkaline agarose gel. The single-stranded probe was purified from the gel and used in the SI nuclease assay. After S1 nuclease digestion, the protected fragment(s) were resolved by electrophoresis on a urea-polyacrylamide gel. For the generation of a probe to detect ns1 mRNA splicing, the NSl gene fragment, including $\mathrm{pBC} 12$ plasmid sequences at the $3^{\prime}$ exon end of the NS1 gene, was cloned into the M13 vector. A 5' end-labeled oligonucleotide complementary to a $\mathrm{pBC} 12$ vector sequence was used to generate a $5^{\prime}$ end-labeled single-stranded DNA probe as described above. This probe detects only the ns1 mRNA transcribed from the NSam 3 gene and the resulting spliced ns2 mRNA but not the unspliceable ns13ss mRNA that directs the synthesis of the NSl protein, because the 3 ' cloning sites of these two NS1 genes in $\mathrm{pBC} 12$ differ.

As internal controls for the S1 nuclease assay, the same amount of RNA that was used in this assay was electrophoresed on $1.2 \%$ agarose-formaldehyde gels. The RNA was transfered to Nytran membranes (Scheicher \& Shuell), which was sequentially hybridized with oligonucleotides specific for the G3PD mRNA and the $45 \mathrm{~S}$ pre-rRNA. The sequences of the $45 \mathrm{~S}$ rRNA and G3PD mRNA hybridization oligonucleotides were GTG TAC CGG AGG TTC CTC ATT CT and GCG ACA GGA GAC CGC TGG ACA GC, respectively, and the hybridization conditions were as described (Barbu and Duatry 1989). Quantitation of the bands in the autoradiographs was performed by densitometry.

\section{Protein purification}

GST-hPABP is a fusion protein between GST and the first 175 amino acids of the human poly(A)-binding protein (hPABP). The sequence of the first 175 amino acids of hPABP was obtained by PCR amplification from the petIla:hPABP plasmid kindly supplied by Gideon Dreyfuss (Görlarch et al. 1994). The PCR fragment was cloned into the BamHI site of the pGEX-3X vector (Pharmacia). The GST-hPABP and GST-NSl fusion proteins were purified by affinity chromatography as described previously (Qiu and Krug 1994). The purity of these proteins was established by gel electrophoresis followed by Coomassie blue staining.
In vitro splicing assays and native gel electrophoresis

A $\beta$-globin minigene in pGEM 1 linearized with EcoRI and the adenovinus pKT1 minigene in sp65 linearized with ScaI were transcribed with SP6 RNA polymerase, as described previously (Agris et al. 1989). The in vitro transcripts contained $\sim 3 \times 10^{7}$ cpm (derived from $\left[\alpha^{-32} \mathrm{p}\right] \mathrm{UTP} / \mu \mathrm{g}$ and contained $\mathrm{m}^{7} \mathrm{GpppG} 5^{\prime}$ ends. Splicing reactions, in a final volume of $20 \mu \mathrm{l}$, were carried out essentially as described previously (Nemeroff et al. 1992). Briefly, the reaction mixtures contained $20 \mathrm{mM} \mathrm{N}-2$ hydroxyethylpiperazine- $N^{\prime}$-2-ethanesulfonic acid (HEPES)-KOH $(\mathrm{pH}$ 7.6), $3.2 \mathrm{mM} \mathrm{MgCl}_{2}, 3 \%$ polyethylene glycol, $0.5 \mathrm{~mm} \mathrm{ATP,} 20$ mM creatine phosphate, $4 \mu \mathrm{g} / \mathrm{ml}$ of creatine phosphokinase, 2 $\mathrm{mm}$ dithiothreitol, $6 \mu \mathrm{l}$ of HeLa cell nuclear extract (containing $20 \mathrm{mg} / \mathrm{ml}$ of nuclear protein), and $10^{5} \mathrm{cpm}$ of labeled RNA transcripts. The splicing reaction mixtures were incubated at $30^{\circ} \mathrm{C}$ for the times indicated. RNA was extracted by pronase digestion and phenol-chloroform extraction (Nemeroff et al. 1992), and the RNA was analyzed by electrophoresis on polyacrylamide- $8 \mathrm{M}$ urea gels. For the $\beta$-globin splicing reactions, $11 \%$ gels were used; and for the adenovirus splicing reactions, $7 \%$ gels were used. The gel loading was checked using Northern blot analysis and $U$ snRNA-specific probes to establish that equal amounts of endogenous U snRNAs were present. Native gel electrophoresis to analyze splicesome formation was carried out according to the method of Konarska and Sharp (1987).

\section{Isolation and characterization of spliceosomes containing the NS1 protein}

The volumes of the splicing reactions (using the adenovirus pre-mRNA) were increased to $35 \mu l$. Where indicated, ATP and the ATP-generating system /creatine phosphate and creatine phosphokinase/ were omitted; or the HeLa cell nuclear extract was preheated at $65^{\circ} \mathrm{C}$ for $5 \mathrm{~min}$ prior to its addition to the splicing reaction. After incubation at $30^{\circ} \mathrm{C}$ for $1 \mathrm{hr}$, the splicing reaction was diluted with $200 \mu \mathrm{l}$ of $\mathrm{IPP}_{150}$ buffer (Hamm et al. 1987) containing $150 \mathrm{~mm} \mathrm{NaCl}$ and $0.1 \% \mathrm{NP}-40$ (ethylphenylpolyethylene glycol). This mixture was added to glutathioneagarose beads, which had been equilibrated with $\mathrm{IPP}_{150}$ buffer, and incubated on a rotator for $1 \mathrm{hr}$ at $4^{\circ} \mathrm{C}$. The beads were washed three times with IPP ${ }_{150}$ buffer and one time with $\operatorname{IPP}_{325}$ buffer containing $325 \mathrm{~mm} \mathrm{NaCl}$. The RNAs that remained bound to the beads were extracted and analyzed by electrophoresis on $7 \%$ polyacrylamide- $8 \mathrm{~m}$ urea gels. After autoradiography, the RNA in the gel was electroblotted onto a Nytran membrane in $0.5 \times \mathrm{TBE}(50 \mathrm{~mm}$ Tris- $\mathrm{HCl}$ at $\mathrm{pH} 7.8,50 \mathrm{~mm}$ boric acid, 1 mM EDTA). The membrane was hybridized with digoxigenincontaining riboprobes specific for the U1, U2, U4, U5, and U6 snRNAs. These probes were synthesized using the snRNA cDNAs from Konarska and Sharp (1987). The amount of the specific snRNA probes hybridized to RNAs in the membrane was determined by colorimetry after incubation with nitroblue tetrazolium and 5-bromo-4-chloro-3-indolyl phosphate (X-phosphate) (Boehringer Mannheim Genius System).

\section{Immunoprecipitation of infected cell extracts}

One $60-\mathrm{mm}$ dish of 293 cells was infected with 20 plaque-forming units (PFUs)/cell of influenza virus UdornA/72 or mockinfected. After $3 \mathrm{hr}$ at $37^{\circ} \mathrm{C}$, cells were harvested and washed with $1 \times$ PBS. The immunoprecipitation procedure was a modification of the method described by Parker et al. (1988). After centrifugation to remove cell debris, the cell extract were added to protein A-agarose beads containing anti-NS1 antiserum or rabbit preimmune serum. To prepare these beads, $10 \mu \mathrm{l}$ of anti- 
NS1 antiserum or rabbit preimmune serum was added to IPP ${ }_{500^{-}}$ washed protein $\mathrm{A}$-agarose beads and incubated with $400 \mu \mathrm{l}$ of IPP $_{500}$ buffer on a rotator at $4^{\circ} \mathrm{C}$ for $1 \mathrm{hr}$. The beads were then washed three times with $1 \mathrm{ml}$ of IPP ${ }_{150}$. After addition of the cell extract, the mixtures were incubated on a rotator at $4^{\circ} \mathrm{C}$ for $1 \mathrm{hr}$. The beads were washed four times with $1 \mathrm{ml}$ of $\operatorname{IPP}_{150}$ and two times with $1 \mathrm{ml}$ of IPP ${ }_{325}$. The RNAs were extracted from the beads and run on a $5 \%$ urea-polyacrylamide gel. The gel was then electroblotted onto Nytran membranes and probed with snRNA-specific probes as described above.

\section{Acknowledgments}

We thank Dr. Martin E. Nemeroff for supplying HeLa cell nuclear extract and Dr. Chaoyin Yin for anti-NS1 antiserum. We thank Helen F. Pirrello for typing this manuscript. This investigation was supported by a National Institutes of Health grant (AI 11772, merit award) to R.M.K.

\section{References}

Agris, C.H., M.E. Nemeroff, and R.M. Krug. 1989. A block in mammalian splicing occurring after formation of large complexes containing U1, U2, U4, U5 and U6 small nuclear ribonucleoproteins. Mol. Cell. Biol. 9: 259-267.

Alonso-Caplen, F.V., M.E. Nemeroff, Y. Qiu, and R.M. Krug. 1992. Nucleocytoplasmic transport: The influenza virus NS1 protein regulates the transport of spliced NS2 mRNA and its precursor NS1 mRNA. Genes \& Dev. 6: 255-267.

Baker, B. 1989. Sex in flies: The splice of life. Nature 340: 521524.

Barbu, V. and F. Dautry. 1989. Northern blot normalization with a $28 \mathrm{~S}$ oligonucleotide probe. Nucleic Acids Res. 17: 7115-7119.

Bell, L.R., J.I. Horabin, P. Schedl, and T.W. Cline. 1991. Positive autoregulation of sex-lethal by alternative splicing maintains the female determined state in Drosophila. Cell 55: 229-239.

Chomcynski, P. and N. Sacchi. 1987. Single-step method of RNA isolation by acid guanidinium thiocyanate-phenolchloroform extraction. Anal. Biochem. 162: 156-159.

Datta, B. and A.M. Weiner. 1991. Genetic evidence for base pairing between $\mathrm{U} 2$ and U6 snRNA in mammalian mRNA splicing. Nature 352: 821-824.

Fortes, P., A. Beloso, and J. Ortin. 1994. Influenza virus NS1 protein inhibits pre-mRNA splicing and blocks mRNA nucleocytoplasmic transport. EMBO J. 13: 704-712.

Furneaux, H.M., K.K. Perkins, G.A. Freyer, J. Arenas and J. Hurwitz. 1985. Isolation and characterization of two fractions from HeLa cells required for mRNA splicing in vitro. Proc. Natl. Acad. Sci. 82: 4351-4355.

Görlarch, M., C.G. Burd, and G. Dreyfuss. 1994. The mRNA poly(A)-binding protein: Localization, abundance and RNAbinding specificity. Exp. Cell Res. 211: 400-407.

Green, M.R. 1989. Pre-mRNA processing and mRNA nuclear export. Curr. Opin. Cell Biol. 1: 519-525

Hadzopoulou-Cladaras, M., B.K. Felber, C. Cladaras, A. Athanssopoulos, A. Tse, and G.N. Pavlakis. 1989. The rev (trs/art) protein of human immunodeficiency virus type 1 affects viral mRNA and protein expression via a cis-acting sequence in the env region. I. Virol. 63: 1265-1274.

Hamm, J., M. Kamaier, and I.W. Mattaj. 1987. In vitro asssembly of U1 snRNPs. EMBO /. 6: 3479-3485.

Hanly, S.M., L.T. Rimsky, M.H. Malim, J.H. Kim, J. Hauber, M. Duc Dudon, S-Y. Le, J.V. Maizel, B.R. Cullen, and W.C.
Greene. 1989. Comparative analysis of the HTLV-1 Rex and HIV-1 Rev trans-regulatory proteins and their RNA response elements. Genes \& Dev. 3: 1534-1544.

Inoue, K., K. Hishijima, H. Sakamoto, and Y. Shimura. 1990. Binding of Drosophia sex-lethal gene product to the alternative splice site of transformer primary transcript. Nature 344: 461-463.

Katze, M.G., and R.M. Krug. 1984. Metabolism and expression of RNA polymerase II transcripts in influenza virus-infected cells. Mol. Cell. Biol. 4: 2198-2206.

Kjems, J., A.D. Frankel, and P.A. Sharp. 1991. Specific regulation of mRNA splicing in vitro by a peptide from HIV-1 Rev. Cell 67: 169-178.

Konarska, M.M. and P.A. Sharp. 1987. Interactions between small nuclear ribonucleoprotein particles in formation of spliceosomes. Cell 49: 763-774.

Krainer, A.R. and T. Maniatis. 1984. Normal and mutant human $\beta$-globin pre-mRNAs are faithfully and efficiently spliced in vitro. Cell 36: 993-1005.

Krainer, A.R., G.C. Conway, and D. Kozak. 1990. The essential pre-mRNA splicing factor SF2 influences 5 ' splice site selection by activating proximal sites. Cell 62: 35-42.

Krug, R.M. 1993. The regulation of export of mRNA from nucleus to cytoplasm. Curr. Opin. Cell Biol. 5: 944-949.

Krug, R.M., F.V. Alonso-Caplen, I. Julkunen, and M.G. Katz. 1989. Expression and replication of the influenza virus genome. In The influenza viurses (ed. R.M. Krug), pp. 89-152. Plenum Press, New York.

Lamb, R.A. and C.-J. Lai. 1984. Expression of unspliced NS1 mRNA, spliced NS2 mRNA, and a spliced chimera mRNA from cloned influenza virus NS DNA in an SV40 vector. Virology 135: 139-147.

Legrain, P. and M. Rosbash. 1989. Some cis-and trans-acting mutants for splicing target pre-mRNA to the cytoplasm. Cell 57: 573-583.

Lesser, C.F. and C. Guthrie. 1993. Mutations in U6 snRNA that alter splice site specificity: Implications for the active site. Science 262: 1982-1988.

Madhani, H.D. and C. Guthrie. 1992. A novel base-pairing interacton between $\mathrm{U} 2$ and U6 snRNAs suggests a mechanism for the catalytic activation of the spliceosome. Cell 71: 803817.

Malim, M.H., J. Hauber, S-Y. Le, J.V. Maizel, and B.R. Cullen. 1989. The HIV-1 rev trans-activator acts through a structural target sequence to activate nuclear export of unspliced viral mRNA. Nature 338: 254-257.

Nemeroff, M.E., U. Utans, A. Kramer, and R.M. Krug. 1992. Identification of cis-acting intron and exon regions in influenza virus NS1 mRNA that inhibit splicing and cause the formation of aberrantly sedimenting presplicing complexes. Mol. Cell. Biol. 12: 962-970.

Parker, K.A., J.P. Bruzik, and A. Steitz. 1988. An in vitro interaction between the human U3 srRNP and 28s rRNA sequences near the $\alpha$-sarcin site. Nucleic Acids Res. 16: 10493-10509.

Perkins, K.K., H.M. Furneaux, and J. Hurwitz. 1986. RNA splicing products formed with isolated fractions from HeLa cells are associated with fast-sedimenting complexes. Proc. Nat1. Acad. Sci. 83: 887-891.

Plotch, S.J., M. Bouloy, I. Ulmanen, and R.M. Krug. 1981. A unique cap $\left(\mathrm{m}^{7} \mathrm{GpppX} \mathrm{X}^{\mathrm{m}}\right)$-dependent influenza virion endonuclease cleaves capped RNAs to generate the primers that initiate viral RNA transcription. Cell 23: 847-858.

Qian, X.Y., F. Alonso-Caplen, and R.M. Krug. 1994. Two functional domains of the influenza virus NS1 protein are required for regulation of nuclear export of mRNA. I. Virol. 
Lu et al.

68: 2433-2441.

Qiu, Y. and R.M. Krug. 1994. The influenza virus NS1 protein is a poly(A)-binding protein that inhibits nuclear export of $m R$ NAs containing poly(A). I. Virol. 68: 2425-2432.

Singh, R. and M.R. Green. 1993. Sequence-specific binding of transfer RNA by glyceraldehyde-3-phosphate dehydrogenase. Science 259: 365-368.

Sontheimer, E.J. and J.A. Steitz. 1993. Identification of U5 and U6 small nuclear RNA's as active site components of spliceosome. Science 262: 1989-1996.

Tian, M. and T. Maniatis. 1992. Positive control of pre-mRNA splicing in vitro. Nature 256: $237-240$.

Wolff, T. and A. Bindereif. 1993. Conformational changes of U6 during the spliceosome cycle: An intramolecular helix is essential both for initiating the U4-U6 interaction and for the first step of splicing. Genes \& Dev. 7: 1377-1389.

Wu, J.A. and J.L. Manley. 1991. Base pairing between U2 and U6 snRNAs is necessary for splicing of a mammalian premRNA. Nature 352: 818-821. 


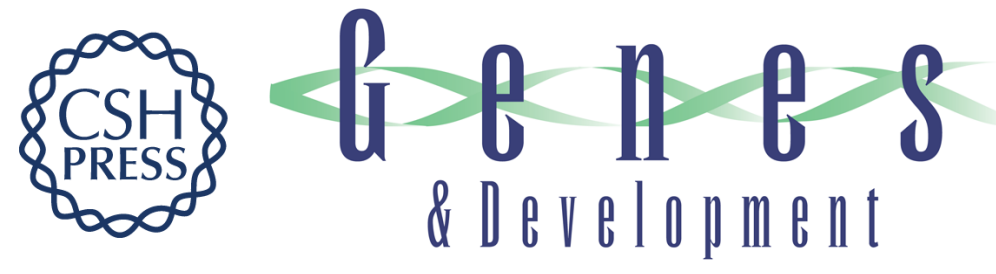

\section{The influenza virus NS1 protein: a novel inhibitor of pre-mRNA splicing.}

Y Lu, X Y Qian and R M Krug

Genes Dev. 1994, 8:

Access the most recent version at doi:10.1101/gad.8.15.1817

References This article cites 37 articles, 14 of which can be accessed free at:

http://genesdev.cshlp.org/content/8/15/1817.full.html\#ref-list-1

License

Email Alerting

Service

Receive free email alerts when new articles cite this article - sign up in the box at the top right corner of the article or click here.

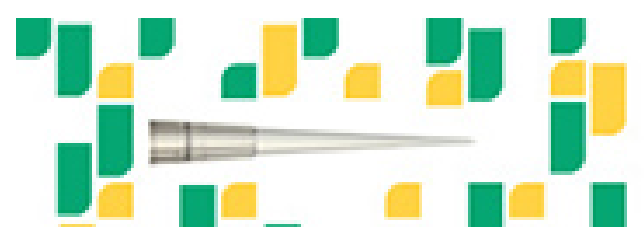

Focused on your science.

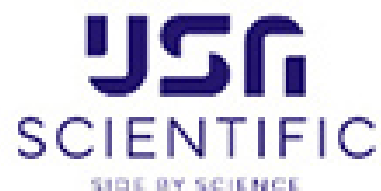

Copyright (c) Cold Spring Harbor Laboratory Press 